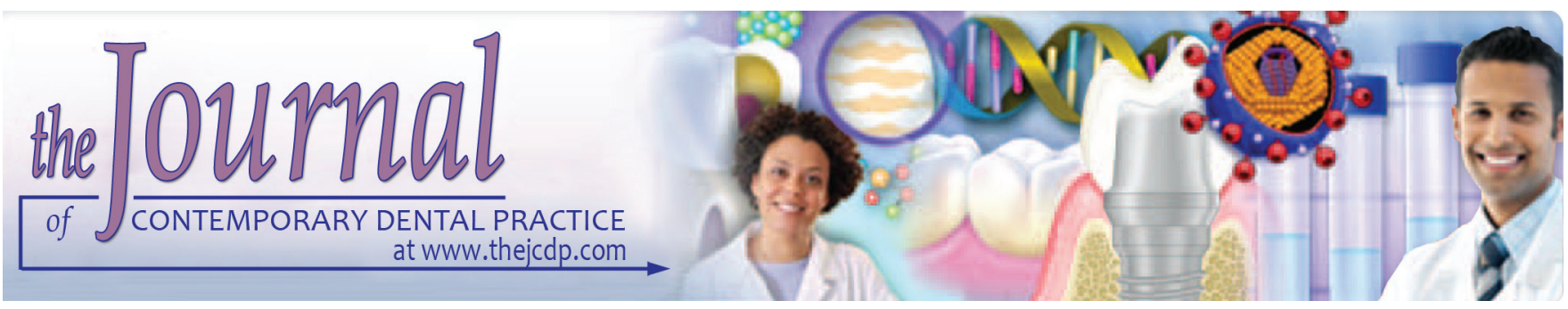

\title{
Impact of Oral Health and Sociodemographic Factors on Quality of Life: A Cross-sectional Study
}

\author{
${ }^{1}$ Rafaella de S Leão, ${ }^{2}$ Juliana RS Maior, ${ }^{3}$ Fábio C Pereira, ${ }^{4}$ Gabriela QM Monteiro, ${ }^{5}$ Sandra LD de Moraes
}

\begin{abstract}
Aim: The aim of this study was to determine the impact of oral health and socioeconomic variables on the quality of life in a sample of low-income Brazilians.

Materials and methods: The sample consisted of 400 adults assisted by the Rescuing Smiles Social Program (Pernambuco University) in June 2014 in the town of Arcoverde, Pernambuco. Two 18+ physically and mentally healthy people were chosen to participate in the study per household. The data obtained were analyzed using Kruskal-Wallis and Mann-Whitney tests.
\end{abstract}

Results: About $75 \%$ of participants were female, averaging 42.65 years; $59 \%$ had elementary schooling and $27 \%$ were illiterate; $63 \%$ of them needed dental restorative treatment, $59.5 \%$ periodontal, and $43.3 \%$ surgical procedures; and $68.2 \%$ of the respondents showed partial tooth loss, $22.8 \%$ were totally edentulous, and $9 \%$ had full dentition. Oral health impact profile (OHIP)-14 average score was 14.91, considered low. The highest averages were observed in low-income individuals (16.25). Individuals with total or partial tooth loss had an average 14.26 and 15.79 , respectively, thus showing a statistically significant difference as compared with total dentate (9.86).

Conclusion: Although low-income individuals with tooth loss showed the highest OHIP-14 averages, it could be concluded that oral condition did not affect the quality of life of most individuals in the population studied.

Clinical significance: Thus, oral health did not have a significant impact on respondent health awareness. This study showed the need to better inform the public of the relevance of oral health to quality of life.

Keywords: Oral health, Oral health impact profile-14, Quality of life.

How to cite this article: de S Leão R, Maior JRS, Pereira FC, Monteiro GQM, de Moraes SLD. Impact of Oral Health and

${ }^{1-5}$ Department of Prosthodontics, School of Dentistry, Pernambuco University (UPE) Camaragibe, Pernambuco, Brazil

Corresponding Author: Sandra LD de Moraes, Department of Prosthodontics, School of Dentistry, Pernambuco University (UPE), Camaragibe, Pernambuco, Brazil, Phone: +5581985554539, e-mail: sandra.moraes@upe.br
Sociodemographic Factors on Quality of Life: A Cross-sectional Study. J Contemp Dent Pract 2018;19(4):438-442.

Source of support: Nil

Conflict of interest: None

\section{INTRODUCTION}

Oral health-related quality of life is known as a multidimensional construct, subjective evaluation of the individual's oral health, which includes emotional and functional well-being, and sense of the self. Knowledge of disease and oral condition influencing on the individual's social function has a great relevance to the scientific community. ${ }^{1}$

The patient's oral health perception must be thought of as a broader concept of health, no longer based only in the absence of disease. In addition, limiting aspects must take into account, not only from the physical but also psychological or social standpoints, emphasizing human individuality. ${ }^{2}$

There has been a tendency toward patient-centered evaluations due to the need to supplement conventional clinical findings. The perception of each individual's particular experiences can assess oral health subjective indicators. ${ }^{3}$

Self-perception indicators are an important tool for the implementation of dental services aimed at specific populations. ${ }^{4}$ To evaluate functional, social, and psychological issues arising from oral diseases, standardized questionnaires have been used for data acquisition, among which is the OHIP developed by Slade and Spencer. ${ }^{5}$ From the initial questionnaire, a simplified version containing seven dimensions, also known as OHIP-14, was validated by Slade ${ }^{6}$ and has been used in different countries. ${ }^{7,8}$ The Brazilian version of the short form of the OHIP-14 was validated by Oliveira and Nadanovsky. ${ }^{9}$

The instrument consists of 14 items related to the impact caused by teeth, dentures, or oral problems. Scores 
are attributed to each response: Never (0), occasionally (1), some of the time (2), most of the time (3), and all of the time (4). For all 14 items, the sum of scores is then interpreted between the minimum (0) and maximum scores (56). The higher the score, the greater the dental or oral problem impact.

The aim of this study was to extend the knowledge of the importance of oral health on life quality, as well as evidence of the oral clinical status of a low-income population living in the hinterland of the State of Pernambuco, Brazil. The hypothesis tested was whether oral health condition affects the quality of life.

\section{MATERIALS AND METHODS}

This study was approved by the Research Ethics Committee of the University of Pernambuco, in agreement with Resolution 466/2006 of the National Health Council, and registered by the Brazil platform under CAAE number 31254014.2.0000.5207.

A cross-sectional study was conducted in the population living in the "Rua do Lixo" (Garbage Street) neighborhood, an area showing high poverty rates located on the outskirts of the town of Arcoverde, Pernambuco State, Brazil. This area has a population of 5,600 dwellers, with an average of 7 people/home. The sample consisted of a universe of 400 individuals defined by statistical calculation. ${ }^{10}$ The formula used to determine the sample size was as follows:

where

$$
m=\frac{z^{2} P_{e}\left(1-P_{e}\right)}{e^{2}} n=\frac{m}{1+\frac{m-1}{N}}
$$

- $\mathrm{n}$ = sample size;

- $\mathrm{z}=$ the value of reliability-related normal curve (1.96);

- $\mathrm{Pe}=$ expected ratio of $0.5(50.0 \%)$, a value that maximizes the sample size;

- $\mathrm{e}=0.05$ error $(5.0 \%)$;

- $\mathrm{N}=$ population size $=5600$.

Data were collected during the extension Program Rescuing Smiles held in Arcoverde-PE, Brazil, in June 2014. A team of 10 senior undergraduate students and 3 postgraduate students coordinated by a researcher visited the houses, which were chosen randomly for sample collection through a systematic sampling, where one in every three houses was visited.

Data collection per dwelling included a maximum of two people over the age of 18 who were physically and mentally apt to respond to the survey (inclusion criteria). Those who refused to sign the informed consent form or who presented some cognitive inability to respond to the questionnaire were excluded from the study.

Data collection was performed by means of a sociodemographic questionnaire that included the following information: Sex, age, marital status, schooling, and income.

Oral health condition was evaluated through a clinical form based on data collected by the SB Brazil Project, ${ }^{11}$ which was a National Oral Health Survey involving the Brazilian population in 2010.

Clinical examination was performed in loco under direct lighting (aided by a flashlight) using wooden spatulas. Tooth condition was classified as totally edentulous (complete absence of teeth), partially dentate (a tooth or more missing), and fully dented. Treatment requirements were then classified as restorative (presence of decayed or fractured teeth), periodontal (presence of supragingival calculus and tooth mobility), and surgical (tooth extraction indication). The OHIP-14 in the Portuguese language (Table 1) was then applied to each participant.

A factor that had to be taken into account as an eventual risk of bias in the study was the understanding of the OHIP-14 questions by the studied population, once they had little schooling.

The data were organized in Microsoft Excel ${ }^{\circledR}$ worksheet and were descriptively analyzed as absolute frequencies and percentages, and measures of central tendency were obtained. Statistical calculations were done by Statistical Package for Social Sciences, version 21 software. Equality of variances and normality tests were evaluated by Levene's F test and Shapiro-Wilk test, respectively. Kruskal-Wallis and Mann-Whitney tests were also used. The margin of error for statistical tests was $5 \%$.

With regard to self-perception results, for the purpose of validating the questionnaire, Cronbach's alpha test was initially applied to check the internal consistency of the OHIP-14 index.

\section{RESULTS}

All descriptive data are shown in Table 2. The age ranged between 18 and 95 years with an average of 42.65 years. The majority of the respondents were between 18 and 39 years $(51.8 \%)$, and $75.0 \%$ were females. Most of the individuals only had primary schooling (59.5\%), whereas $27.0 \%$ were illiterate. With reference to income, the majority $(66.3 \%)$ earned less than one minimum wage (U\$ 221) followed by $22.0 \%$ who had an income of one minimum wage, thus characterizing a low-income population.

As to oral health, $68.3 \%$ were partially edentulous, followed by $22.8 \%$ edentulous, and $9.0 \%$ totally dentate. The majority of the respondents $(63.0 \%)$ needed restorative treatment, followed by periodontal treatment (59.5\%) and surgical treatment (43.3\%).

Cronbach's alpha test was initially applied to check the internal consistency of the OHIP-14 index. When considering the total number of questions that make up 
Table 1: Oral health impact profile (simplified questionnaire)

\begin{tabular}{|c|c|c|}
\hline Dimension & Question & Answers/scores \\
\hline Functional limitations & $\begin{array}{l}1 \text { Have you had speech difficulties because of tooth, mouth, } \\
\text { or gum problems? } \\
2 \text { Have you ever realized that the taste of food got worse } \\
\text { because of tooth, mouth, or gum problems? }\end{array}$ & $\begin{array}{l}\text { Never (0), occasionally (1), some of the } \\
\text { time (2), most of the time (3), all of the } \\
\text { time (4) }\end{array}$ \\
\hline Physical pain & $\begin{array}{l}3 \text { Do you ever feel pain in your mouth or teeth? } \\
4 \text { Have you ever felt uncomfortable eating some food } \\
\text { because of tooth, mouth, or gum problems? }\end{array}$ & \\
\hline Psychological distress & $\begin{array}{l}5 \text { Have you ever been worried about tooth, mouth, or gum } \\
\text { problems? } \\
6 \text { Have you ever been stressed because of tooth, mouth, or } \\
\text { gum problems? }\end{array}$ & \\
\hline Physical limitations & $\begin{array}{l}7 \text { Have your feeding habits ever been impaired because of } \\
\text { tooth, mouth, or gum problems? } \\
8 \text { Have you ever had to interrupt a meal because of tooth, } \\
\text { mouth, or gum problems? }\end{array}$ & \\
\hline Psychological limitations & $\begin{array}{l}9 \text { Have you ever found it difficult to relax because of tooth, } \\
\text { mouth, or gum problems? } \\
10 \text { Have you ever been embarrassed because of tooth, } \\
\text { mouth, or gum problems? }\end{array}$ & \\
\hline Social limitations & $\begin{array}{l}11 \text { Have you ever been angry with others because of tooth, } \\
\text { mouth, or gum problems? } \\
12 \text { Have you had difficulty in performing daily activities } \\
\text { because of tooth, mouth, or gum problems? }\end{array}$ & \\
\hline Inabilities & $\begin{array}{l}13 \text { Have you ever felt that your quality of life in general has } \\
\text { worsened because of tooth, mouth, or gum problems? } \\
14 \text { Have you ever been totally unable to do your daily } \\
\text { activities because of tooth, mouth, or gum problems? }\end{array}$ & \\
\hline
\end{tabular}

Table 2: Oral health self-perception distribution in the population studied according to sociodemographic variables

\begin{tabular}{|c|c|c|c|c|c|}
\hline \multirow[b]{2}{*}{ Variable } & \multicolumn{5}{|c|}{ Statistics } \\
\hline & Mean $\pm S D$ & Quartile 1 & Median & Quartile 3 & $p$-value \\
\hline \multicolumn{6}{|l|}{ Age group } \\
\hline $18-39$ & $14.36 \pm 10.10^{\mathrm{ab}}$ & 7.00 & 12.00 & 20.00 & $0.049^{* 1}$ \\
\hline $40-59$ & $16.93 \pm 12.08^{a}$ & 8.00 & 15.50 & 24.25 & \\
\hline 60 or older & $13.61 \pm 12.13^{b}$ & 5.00 & 10.00 & 21.00 & \\
\hline \multicolumn{6}{|l|}{ Sex } \\
\hline Male & $14.44 \pm 11.34$ & 7.00 & 12.00 & 20.75 & $0.521^{2}$ \\
\hline Female & $15.07 \pm 11.10$ & 6.00 & 13.00 & 22.00 & \\
\hline \multicolumn{6}{|l|}{ Marital status } \\
\hline Single & $14.24 \pm 10.62$ & 6.00 & 12.00 & 20.00 & $0.302^{2}$ \\
\hline Married & $15.62 \pm 11.67$ & 6.00 & 13.00 & 24.00 & \\
\hline \multicolumn{6}{|l|}{ Schooling } \\
\hline Illiterate & $16.25 \pm 12.97$ & 6.00 & 13.00 & 23.75 & $0.271^{1}$ \\
\hline Elementary & $14.92 \pm 10.70$ & 6.00 & 13.00 & 22.00 & \\
\hline High school/higher education & $12.22 \pm 8.55$ & 6.75 & 12.00 & 18.00 & \\
\hline \multicolumn{6}{|l|}{ Income (in minimal wages) } \\
\hline$<1$ & $16.07 \pm 11.39^{a}$ & 7.00 & 14.00 & 23.00 & $0.002^{* 1}$ \\
\hline 1 & $13.32 \pm 10.98^{b}$ & 5.25 & 10.00 & 19.00 & \\
\hline Above 1 & $10.26 \pm 7.84^{b}$ & 5.25 & 9.50 & 14.25 & \\
\hline
\end{tabular}

Different superscript letters indicate significant differences between categories; ${ }^{1}$ Kruskal-Wallis test by comparison to the same test;

${ }^{2}$ Mann-Whitney test; SD: Standard deviation; *Statistically significant difference

the OHIP-14 index, good internal consistency (Cronbach's alpha $=0.88)$ was verified. The OHIP-14 average score was 14.91.

The OHIP-14 average score was higher for the 40 to 59 age group (16.93) and ranged between 13.61 and 14.36 for the other two age groups. There were significant differences between the 40- and 59-year-old group and the $60+$ group.

The OHIP-14 average score was reduced according to income range, with a 16.07 average among those who 
Impact of Oral Health and Sociodemographic Factors on Quality of Life

Table 3: Oral health self-perception distribution in the population studied according to tooth presence

\begin{tabular}{|c|c|c|c|c|c|}
\hline \multirow[b]{2}{*}{ Variable } & \multicolumn{5}{|c|}{ Statistics } \\
\hline & Mean $\pm S D$ & Quartile 1 & Median & Quartile 3 & $p$-value \\
\hline \multicolumn{6}{|l|}{ Type of dentition } \\
\hline Totally edentulous & $14.26 \pm 11.77^{a}$ & 6.00 & 12.00 & 20.00 & $0.007^{* 1}$ \\
\hline Partially edentulous & $15.79 \pm 11.16^{a}$ & 7.00 & 14.00 & 23.00 & \\
\hline Totally dentate & $9.86 \pm 7.71^{\mathrm{b}}$ & 3.00 & 8.50 & 13.00 & \\
\hline
\end{tabular}

Different superscript letters indicate significant differences between categories; ${ }^{1}$ Kruskal-Wallis test by comparison to the same test; SD: Standard deviation

had an income lower than the minimum wage and 10.26 for the group who earned more than a minimum wage. Income influenced the OHIP average, showing higher averages for lower income individuals. Overall averages were, however, low.

In the full dentition variable (Table 3 ), the total average score was lower among the totally dentate (9.86) and ranged from 14.26 to 15.79 in the other two categories, with a significant difference between totally dentate and the other two categories.

\section{DISCUSSION}

Quality of life is defined by the World Health Organization as "the individual's perception of their position in life, in the context of the culture and value systems in which they live and in relation to their goals, expectations, standards and concerns." 12 Taking this into consideration, the perception of the oral condition and its importance is part of what influences the behavior of the individual, ${ }^{13}$ so it is fundamental to study this perception of the patient. The hypothesis of this study was rejected, since oral health condition did not interfere in the studied individuals' quality of life.

Health-related quality-of-life perception may be influenced by factors such as poor general health and life stress, ${ }^{14}$ age, gender, cultural aspects, socioeconomic status, and tooth loss. ${ }^{6}$

The results of this study revealed that the highest OHIP-14 scores were found for individuals in the 40 to 59 age groups. Conversely, Papagianni et $\mathrm{al}^{15}$ stated that the impact of oral health problems decreases with age, regardless of the presence of teeth. This suggests that oral function expectations and demands may decline as people grow old. ${ }^{2}$

There were no significant differences in the studied index between males and females. Nevertheless, a study by Botello-Harbaum et al ${ }^{16}$ showed a higher oral health impact on quality of life in women.

Different educational backgrounds also did not interfere with quality-of-life perception. However, Tsakos et $\mathrm{al}^{17}$ reported that the educational background has an indirect adverse effect on the quality of life of elderly patients. Individuals with higher schooling showed lower
OHIP-14 scores, thus pointing to a better oral health condition. This could be explained by the fact that the higher level of schooling is associated with a higher level of income and more information, which determines a greater search for dental services by this working population, which in turn implies a smaller impact on quality of life. ${ }^{18}$

The higher the educational level, the greater is the demand for information and search for dental services. ${ }^{19}$ Therefore, the scholarly level of a subject has a significant impact on the quality of life, although the results of this study did not show this fact. The absence of such evidence is possibly due to the little variation of educational levels within the studied population sample.

Most of the individuals studied had low incomes, and the financial condition showed statistically significant higher scores. This is in agreement with the findings of Bilic et al. ${ }^{2}$ It is believed that this is due to a more restricted access to health services.

With respect to oral health, there were a high percentage of individuals who needed restorative and periodontal interventions, in addition to a large number of partially or totally edentulous subjects. Despite clinical findings, OHIP-14 score averages were low, leading to the conclusion that oral health was not an impacting factor on the quality of life of the population under study. This finding may be attributed to the high poverty level of the respondents, whose basic needs were not being attended to, as well as the lack of access to health services and low schooling rates.

Individuals with full dentition showed a better quality of life as compared with those who were either totally or partially edentulous.

This statement is in consonance with the affirmations made by Ekanayake and Perera, ${ }^{20}$ which declare that although the improvement of mastication, speech, and esthetics is observed in users with complete denture, when compared with patients that do not require the use of prosthesis, OHIP values are more favorable for the latter group.

The findings of this study emphasize the influence of cultural aspects on the quality-of-life impact, such as the accepted belief in Brazil that tooth loss is part of the aging process. 
Despite these findings, the OHIP-14 average score was low, showing that, regardless of the low schooling rates, the unfavorable economic situation, and the large number of individuals with tooth loss or in need of oral interventions, the general index that evaluates the impact of oral health on quality of life was positive. Thus, oral health did not have a significant impact on respondent health awareness.

This study showed the need to better inform the public of the relevance of oral health to quality of life. Despite the existing media reach that counts even with the vast coverage of the internet to the most distant cities, many people still do not use this resource for the purpose of health education. This is perhaps because of the lack of awareness or even the lack of interest in seeking information to improve their oral health. We can raise the possibility that in the population studied, there is no enough critical literacy. This is being characterized as the individual's ability to critically analyze information and use it to have greater control over life situations, in which we can include the oral health. ${ }^{21}$

In an attempt to change the situation found, the town administration was reported on the dental needs of the population so that actions aimed at a population health improvement could be taken.

Although individuals with lower income and some tooth loss had the highest OHIP-14 averages, attributed scores were nevertheless low. It was concluded that oral health did not affect the quality of life of most individuals in the studied population.

One point that should be highlighted is that as the study presents a cross-sectional nature, the analyses carried out possess a momentary evaluation, that is, the interpretation is done based on temporality. One point that could alter the results would be the uniformity of the sociodemographic situation of the studied population, even if this population was the objective of the study.

\section{CONCLUSION}

Although lower income individuals with tooth loss showed the highest OHIP-14 averages, it could be concluded that oral condition did not affect the quality of life of most individuals in the population studied.

\section{REFERENCES}

1. Sischo L, Broder HL. Oral health-related quality of life: what, why, how, and future implications. J Dent Res 2011 Nov;90(11):1264-1270.

2. Bilic S, Blomberg I, Burry K, Chong E, Yeung E, Ariyawardana A. Oral-health-related quality of life of dental patients: a hospital based study in far north Queensland, Australia. J Investig Clin Dent 2017 Aug;8(3):1-6.

3. Kim HY, Jang MS, Chung CP, Paik DI, Park YD, Patton LL, $\mathrm{Ku}$ Y. Chewing function impacts oral health-related quality of life among institutionalized and community-dwelling Korean elders. Community Dent Oral Epidemiol 2009 Oct;37(5):468-476.

4. Henriques C, Telarolli Júnior R, Loffredo LC, Montandon AA, Campos JA. Autopercepção das condições de saúde bucal de idosos do município de Araraquara-SP. Cien Odontol Bras 2007 Jul-Sep;10(3):67-73.

5. Slade GD, Spencer AJ. Development and evaluation of the oral health impact profile. Community Dent Health 1994 Mar;11(1):3-11.

6. Slade GD. Derivation and validation of a short-form oral health impact profile. Community Dent Oral Epidemiol 1997 Aug;25(4):284-290.

7. Navabi N, Nakhaee N, Mirzadeh A. Validation of a Persian version of the oral health impact profile (OHIP-14). Iran J Public Health 2010 Dec;39(4):135-139.

8. Montero-Martín J, Bravo-Pérez M, Albaladejo-Martínez A, Hernández-Martín LA, Rosel-Gallardo EM. Validation the oral health impact profile (OHIP-14sp) for adults in Spain. Med Oral Patol Oral Cir Bucal 2009 Jan;14(1):E44-E50.

9. Oliveira BH, Nadanovsky P. Psychometric properties of the Brazilian version of the oral health impact profile-short form. Community Dent Oral Epidemiol 2005 Aug;33(4):307-314.

10. Zar, H. Biostatistical analysis/Jerrold. 4th ed. New Jersey: Prentice Hall; 1999. p. 529.

11. Brazil, Ministry of Health (MH). SB project Brazil 2010: main results. Brasília: MH; 2011.

12. da Costa EH, Saintrain MV, Vieira AP. Autopercepção da condição de saúde bucal em idosos institucionalizados e não institucionalizados. Ciên Saúde Colet 2010 Sep;15(6): 2925-2930.

13. Silva SR, Fernandes RA. Autopercepção das condições de saúde bucal por idosos. Rev Saúde Públ 2001 Aug;35(4): 349-355.

14. Locker D, Slade G. Association between clinical and subjective indicators of oral health status in an older population. Gerodontology 1994 Dec;11(2):108-114.

15. Papagianni CE, van der Meulen MJ, Naeije M, Lobbezoo F. Oral health-related quality of life in patients with tooth wear. J Oral Rehabil 2013 Mar;40(3):185-190.

16. Botello-Harbaum MT, Matthews AG, Collie D, Vena DA, Craig RG, Curro FA, Thompson VP, Broder HL; PEARL Network. Level of oral health impacts among patients participating in PEARL: a dental practice-based research network. Community Dent Oral Epidemiol 2012 Aug;40(4):332-342.

17. Tsakos G, Sheiham A, Iliffe S, Kharicha K, Harari D, Swift CG, Gillman G, Stuck AE. The impact of educational level on oral health-related quality of life in older people in London. Eur J Oral Sci 2009 Jun;117(3):286-292.

18. Guerra MJ, Greco RM, Leite IC, Ferreira eFerreira F, dePaulaMV. Impact of oral health conditions on the quality of life of workers. Ciên Saúde Colet 2014 Dec;19(12):4777-4786.

19. Mesquita FA, Vieira S. Impacto da condição autoavaliada de saúde bucal na qualidade de vida. Rev Gaucha Odontol 2009 Oct-Dec;57(4):401-406.

20. Ekanayake L, Perera I. A associação entre o estado clínico de saúde bucal e os impactos orais experimentados por idosos no Sri Lanka. J Reabil Oral 2004;31:831-836.

21. Nutbeam D. Alfabetização em saúde como objetivo de saúde pública: um desafio para uma educação sanitária contemporânea e estratégias de comunicação para o século XXI. Health Promot Int 2000; 15(3)259-267. 